\title{
KONGRESSKALENDER
}

\section{November 2021}

05./06.11.2021, Lüneburg Jenseits von Beziehung?

Dissozialiät in psychiatrischen Kontexten Norddeutschen Arbeitsgemeinschaft Psychodynamische Psychiatrie (NAPP) Ort: Lüneburg, Psychiatrisches Krankenhaus Information: Holger Selig <holgselig@ aol.com>

17.-20.11.2021 Chicago (USA) Hybrid-

Tagung

American Society of Criminology -

76th Annual Meeting

Science and Evidenced-Based Policy in a Fractured Era

Chicago, Palmer House Hilton

Information: https://asc41.com/events/2021asc-annual-meeting/

\section{März 2022}

02.-04.03.2022, Lippstadt-Eickelborn,

Hybrid-Tagung

35. Eickelborner Fachtagung zu Fragen der Forensischen Psychiatrie

Dr. Wallenstein

Kontakt: Birgit Lummer, https://www. lwl-forensik-lippstadt.de/de/eickelbornerfachtagung/

\section{Mai 2022}

27.05.2022, Dresden

26. Dresdner Frühjahrstagung für

Forensische Psychiatrie

Persönlichkeitsstörungen - Wandlungen

im forensischen Kontext

Dr. Lange, Prof. Dr. Bauer, Dr. Lammel, Dr. Sutarski

Information: www.forensik-dresden.de

\section{Juni 2022}

17.06.2022, Berlin-Mitte, hybrid 25. Berliner Junitagung für Forensische Psychiatrie und Psychologie

Forensische Psychiatrie Psychologie Berlin e. V. (FPPB) \&

Institut für Forensische Psychiatrie der

Charité

Langenbeck-Virchow-Haus

Information: www.forensik-berlin.de (Veranstaltungen)

Juni 2022, Ort wird noch bekanntgegeben 23th Annual IAFMHS Conference Forensic Mental Health Services Information: www.iafmhs.org

\section{Oktober 2022}

Oktober 2022, München

35. Herbsttagung für Forensische Psychiatrie

Abteilung für Forensische Psychiatrie der Universität München

Prof. Dr. Schiltz

Information: www.forensik-muenchen.de

26.-29.10.2022, NN

Association for the Treatment of Sexual Abusers (ATSA)

41st Annual Research and Treatment Conference

Information: http://www.atsa.com/futureatsa-conferences

Oktober 2022, N. N. (USA)

American Academy of Psychiatry and the Law

53rd Annual Meeting (with APA)

Information: www.AAPL.org

Hinweise für den Kongresskalender bitte an: mail@hlkroeber.de 